\title{
THE SPOTTING OF PLATED OR FINISHED METALS
}

\author{
By W. P. Barrows ${ }^{1}$
}

ABSTRACT

The American Electroplaters' Society, composed of foremen electroplaters, collected from their branches and from firms engaged in plating, funds to be used for researches on plating. The first problem selected for study was the "spotting out" of plated finishes, a defect which has proven very serious in such industries as the manufacture of builders' hardware.

The investigation showed that there are two quite distinct defects that have been commonly included under the term "spotting out." The "crystal spots" consist of dendritic crystals which appear only on metals having an "oxidized" surface; that is, one colored with copper sulphide oi other sulphides and subsequently lacquered. The "stain spots" appear especially on cast metals, either plain or lacquered, in the form of discolored areas of irregular shape, usually with a small dark spot near the center.

The crystal spots have been found by X-ray examination to consist of cuprous sulphide $\left(\mathrm{Cu}_{2} \mathrm{~S}\right.$ or chalcocite) growing usually between the layer of cuprous sulphide on the metal and the lacquer film. Their formation is caused or accelerated by sulphur in even minute amounts, such as may be derived from sulphur or hydrogen sulphide in the atmosphere or from rubber bands or wrapping paper or cardboard cartons. It was impossible to determine whether these traces of sulphur cause the slow formation of new cuprous sulphide in coarse crystals or the recrystallization of the very fine-grained cuprous sulphide already present.

The only promising remedies are $(a)$ exclusion of sulphur from the surroundings, (b) the use of lacquers found to retard spotting, (c) the application of a thin film of a grease, such as petrolatum, to the lacquered surface, and $(d)$ the use of wax paper for wrapping.

The stain spots are caused by the absorption in pores in the metal of acid or alkaline compounds during the plating process. Upon subsequent exposure to a high humidity such substances absorb moisture and exude upon and stain the surface. It was found that alkaline substances are especially difficult to remove from capillary pores. It is not practicable, however, to eliminate alkaline substances from the cleaning and plating solutions.

In some cases the porosity of the metal may be reduced by a change in pattern or in casting conditions. No method of rinsing or neutralizing was entirely effective in removing the compounds. Baking at high temperatures before lacquering is sometimes helpful.

The two most effective remedies are (a) permitting the chemicals to exude or spot out by exposing the articles to a high humidity before the final finishing, and (b) the application of a lacquer which has been found to retard this type of spotting. In general, phenol-condensation lacquers, which are less permeable to moisture than nitrocellulose lacquers, are also more effective in retarding stain spotting. Permeability to moisture is, however, not the only factor. Tests on many commercial lacquers of both types show that it is possible to develop lacquers which are much more effective for this purpose than the average nitrocellulose lacquers previously employed.

1 Research associate of the American Electroplaters' Society. 


\section{CONTENTS}

I. Introduction....... 1086

II. Crystal spotting

1. Occurrence and composition of crystal spots............ 1088

2. Factors involved. 1090

(a) Method of test empioyed

(b) The base metal............. 1090

(c) The sulphide film............. 1090

(1) Composition of the film _........ 1090

(2) Preparation of the film......... 1091

(d) The protective coating .

(1) Relation of lacquer to spots_._.

(2) Composition of the lacquer.......... 1091

(3) Thickness of the lacquer film

(4) Substitutes for lacquer. _..._._. 1092

(5) Sulphide particles in the lacquer............... 1092

(6) Acidity of the lacquer.......... 1092

(7) Comparison of lacquers._._.

(8) Effect of a film superimposed on the lacquer.

(e) The environment_..._. 1096

(1) Sulphur.

(2) Rubber

(3) Sulphur compounds_._._. 1096

(4) Wrapping materials_._._.

(5) Temperature

(6) Humidity

(7) Effect of oxygen

3. Plant tests...

4. Conclusions. 1103

III. Stain spotting

1. Occurrence and composition of stain spots

2. Factors involved.

(a) Method of test employed........ 1106

(b) The base metal_................. 1106

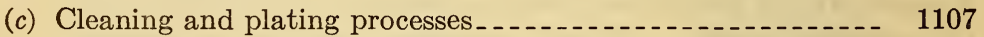

(d) Removal or exclusion of compounds from the pores_._._._- 1108

(e) The protective coating .

(f) The environment.

3. Plant tests...

(a) Gray iron castings.

(b) Brass and bronze.............. 1114

(c) Malleable cast iron $\ldots \ldots \ldots$

(d) Refinished castings.

4. Conclusions._._.

IV. Acknowledgments._._. 1116

\section{INTRODUCTION}

During the past few years the American Electroplaters' Society has collected, through annual subscriptions from its branches and from firms engaged in electroplating, funds to be used for research on 
B. S. Journal of Research, RP72

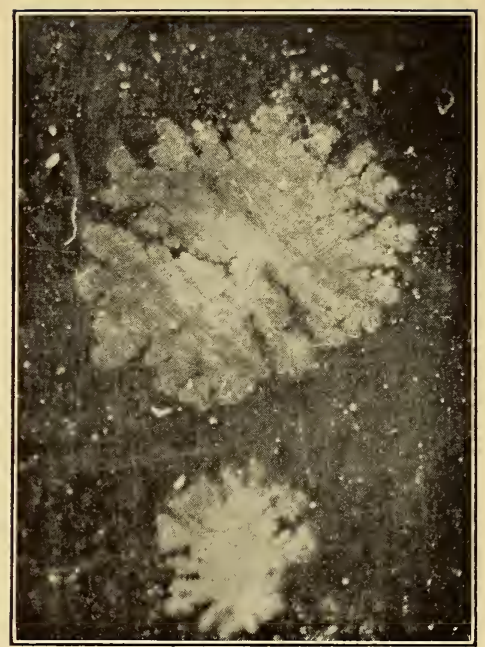

Figure 1.-Typical appearance of crystal spots on sulphide finishes

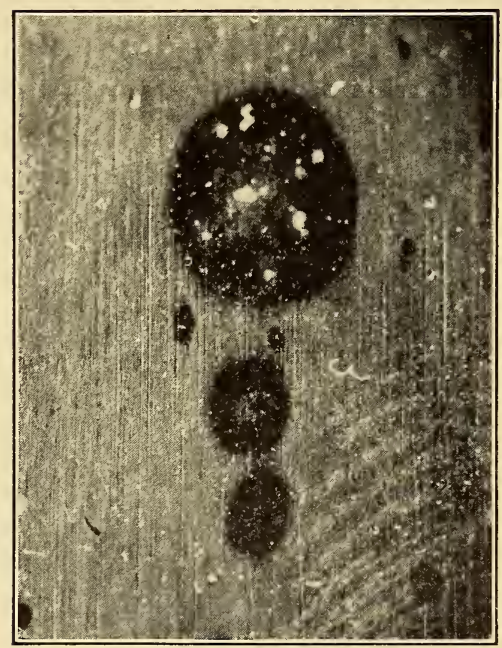

FIguRe 2.-Typical appearance of stain spots caused by chemicals absorbed in pores 
electroplating. This "research fund" has been administered by the research committee of the society and has been used to pay the salaries and certain other expenses of the research associates stationed at the Bureau of Standards. At the suggestion of a number of manufacturers of builders' hardware who subscribed to this fund it was decided to study first a defect of plated metal finishes commonly referred to as "spotting out." This paper is a report of an investigation of that subject conducted by the author during the past two years.

While previous observations by platers had shown that there were different kinds of spotting out, the various types had not been clearly defined or described. Accordingly, a preliminary study of the subject was made through visits to plants and through the examination of specimens received from various sources. These observations showed convlusively that under the term spotting out, as generally used, at least two entirely distinct defects with unrelated causes are commonly referred to. In this paper these will be designated, respectively, as "crystal spotting" and "stain spotting," as these terms usually permit a ready identification of the nature and cause of the spots. These are illustrated in Figures 1 and 2.

Crystal spots occur only upon those metals which have on the surface a film of metal sulphide (commonly referred to as "oxidized" finishes) and a coating of lacquer or similar material. These spots are in the form of black or brown dendritic (treelike) crystals, often radiating from a center or nucleus, and varying in size from those just visible to the eye (or smaller) to those with a diameter of one-eighth inch $(3 \mathrm{~mm})$ or more. The formation of these spots is caused or accelerated by the action of sulphur or sulphur compounds.

Stain spots occur only on porous metals (usually cast metals) which have been subjected to the action of cleaning, pickling, or plating solutions, of which a portion has been retained in the pores, and on evaporation has left compounds in the pores. Upon subsequent exposure of the articles to air containing moisture, the latter is taken up by any deliquescent compounds present in the pores. The resultant solutions spread over the adjacent surface of the metal and form stains or spots of irregular area and variable color, either by their direct action on the metal or by the absorption of sulphur or other substances which discolor the metal.

It is usually possible to distinguish these two types of spots with the eye or with a lens of low magnification. If the sulphide finishes are applied to cast metals, it is quite possible for the two defects to occur upon the same article. In such cases the stain spots are likely to occur within a few days, while crystal spots may not appear until after some weeks or months. 
In a discussion by A. K. Graham at the American Electroplaters' Society in Toronto, in June, 1928, it was pointed out that, the above terms are not entirely exclusive, as the salts which exude from the pores may form crystals on the metal surface. Such crystals are usually light in color and are not likely to be mistaken for the characteristic dark crystals of metal sulphide. Confusion in terms may be avoided by referring, when necessary, to "crystal spotting of sulphide finishes" and to "stain spotting of porous metals."

On the same occasion reference was made to other terms proposed by G. B. Hogaboom to describe these two defects. The former was designated as "spotting in" and the latter as "spotting out." These terms refer to the fact that the sulphide crystals are formed by the action of sulphur from outside sources, while the stains result from compounds exuding from the pores. These terms may also be used, though here, again, the distinction is not sharp, as the "spotting out" (to form stain spots) requires the absorption of moisture from the surrounding atmosphere.

As the two types of spots are quite distinct in their composition and origin, they will be considered separately.

\section{CRYSTAL SPOTTING}

\section{OCCURRENCE AND COMPOSITION OF CRYSTAL SPOTS}

As will be noted later, there are a number of published references and discussions of spotting out, most of which obviously refer to the stain spots. Incidental recognition of crystal spots may be implied but is not clearly defined. At least there has been no known specific research published on this subject. Subsequent to the publication of progress reports of this investigation, N. E. Zadowski ${ }^{2}$ described observations confirming the conclusion of the present author that sulphur causes the formation of crystal spots.

Information received from manufacturers indicated that the spotting of sulphide or oxidized finishes might occur either during storage in the plant or during shipment by train or boat. Practically all accounts agreed that the presence of sulphur in some form accelerated the formation of spots on sulphide finishes. While this type of spotting occurred at all seasons of the year, it was most noticeable from June to September.

Examination of spotted sulphide specimens received from the industry or produced in the laboratory showed that the spots occur only on lacquered finishes in the form of dendritic (treelike) crystals, usually with a black or nearly black color. The crystals grow initially between the lacquer film and the surface of the finish, although they may finally penetrate the lacquer film. Crystals

2 Monthly Review, Am. Electroplaters' Soc., 15, No. 1, p. 4; February, 1928. 
of this type growing between two planes pressed closely together are not uncommon in nature. Specimens were obtained ${ }^{3}$ of magnetite (magnetic oxide of iron) entrapped between flakes of mica which exhibited the same dendritic crystal structure. Another example is the common moss agate.

The fact that these crystals can be formed when only copper and sulphur are present at least indicates that they consist of copper sulphide. Two forms of copper sulphide occur naturally-cupric sulphide $(\mathrm{CuS})$ as the mineral covellite and cuprous sulphide $\left(\mathrm{Cu}_{2} \mathrm{~S}\right)$ as the mineral chalcocite. The crystals present in the spots are exceedingly thin and so light that it is impracticable to collect enough for a chemical analysis. Mineralogic and petrographic examination also failed to identify the crystals. It was therefore decided to make an X-ray examination. ${ }^{4}$ A small amount of the crystals was obtained by removing the lacquer with butyl acetate, after which the crystals could be floated or brushed off the surface without disturbing the underlayer of black copper sulphide. Some of the latter was also scraped off for comparison. The crystals from half a dozen specimens filled a capillary tube 10 by $0.5 \mathrm{~mm}$. The method consisted in comparing the $\mathrm{X}$-ray diffraction pattern of the crystals directly with that of other substances of known composition. Comparisons were made by placing the materials in the opposite ends of the same capillary tube, separating the two substances with a cotton plug, and projecting the two patterns on the same film.

In this way comparisons were made between $(a)$ the black sulphide present in the sulphide coating, (b) the crystals removed from the surface, $(c)$ the mineral ${ }^{5}$ chalcocite, $(d)$ the mineral covellite, and $(e)$ cupric oxide. The results showed conslusively that the patterns of $(a),(b)$, and $(c)$ were identical and quite different from those of $(d)$ and (e). It is evident, therefore, that both the original coating and the crystals which formed on it, consist of cuprous sulphide, $\mathrm{Cu}_{2} \mathrm{~S}$.

The crystals of cuprous sulphide may conceivably be formed in either of two ways; $(a)$ by a recrystallization of the much finer (but also crystalline) coating of cuprous sulphide produced by the action of polysulphides on the copper or $(b)$ the formation of new cuprous sulphide by the slow action of sulphur upon minute areas of copper that may be exposed through the original sulphide film. The latter view is rendered more probable by the fact that (1) the crystal formation is accelerated by sulphur vapor and (2) the crystals are more likely to form where there is a slight scratch which may penetrate not only the lacquer but also the sulphide film: At best, it is difficult to fully explain the formation of these crystals. It is possible that

3 Through the courtesy of E. T. Wherry, of the United States Bureau of Chemistry and Soils.

4 All X-ray analyses were made by F. Sillers, jr., of the Bureau of Standards.

The author is indebted to H E. Merwin, of the Geophysical Laboratory, for these mineral specimens. 
the presence of small amounts of sulphur simply accelerates the formation of the visible crystals by the recrystallization of the finergrained coating of cuprous sulphide.

\section{FACTORS INVOLVED}

(a) METHOD OF TEST EMPLOYED

Because the occurrence of crystal spots is not uniform or quantitative under most conditions, it was necessary to subject at least 10 or 20 specimens to each set of conditions to obtain reliable "average" performances. Most of the specimens were prepared in the laboratory, but whenever feasible corresponding plant samples were included in the tests. All specimens were dip lacquered unless otherwise stated.

In order to obtain at least comparative results in a short time, an accelerated test was developed after certain preliminary experiments had been made. Unless otherwise stated, the tests were made by storing the specimens in contact with rubber bands or flowers of sulphur. Under these conditions spots usually appeared within one to three days, while in many cases in the absence of sulphur or rubber one to three months elapsed before the appearance of the spots.

(b) THE BASE METAL

In order to determine whether the metal on which the sulphide finish is applied affects the tendency for the crystal spots to form, tests were made with sulphide finishes on sheet copper and brass and on sheet steel plated with copper or brass. The results showed that there is no difference in the behavior of these metals. It is evident, therefore, that the crystal spots are connected with the copper itself and not with the metal underlying it.

\section{(c) THE SULPHIDE FILM}

(1) Composition of the Film.-Experiments were made with black films produced on copper or brass by (1) the action of sodium or potassium polysulphide solutions, (2) black nickel plating from sulphocyanate solutions, (3) black nickel plating from nickel chloride solutions containing no sulphur, (4) copper carbonate black, and (5) films produced on silver-plated steel by polysulphide solutions. The results showed that spots appeared only on (1), (2), and (5); that is, those in which sulphur was present. It is interesting to note, however, that while crystal spots can be produced by sulphur acting upon black nickel deposits from sulphocyanate solutions and upon silver sulphide finishes, there is little evidence that crystal spots occur on commercial products of these types.

Although crystal spots appeared on copper sulphide finishes in large numbers within a week, they did not appear on silver sulphide 
until after 8 to 12 weeks' exposure in contact with sulphur, and on black nickel they remained small and inconspicuous after 6 weeks' exposure to sulphur, although they appeared after a week's exposure. Tarnish was more readily produced on the bright areas of relieved silver sulphide films than were crystal spots. While the spots produced on silver sulphide resembled somewhat those formed on copper sulphide, they were more leaflike in appearance. A crystallographic examination ${ }^{6}$ of the spots appearing on silver sulphide finishes indicated that they consist of silver sulphide, $\mathrm{Ag}_{2} \mathrm{~S}$, having the crystal form of the mineral acanthite.

(2) Preparation of the Film.-In order to determine whether any of the materials other than the sulphide used in the preparation of the sulphide films were responsible for the spots, films were produced by exposing to hydrogen sulphide copper that had not been in contact with any acids or alkalies. The black film so produced resembied that made with sodium or potassium polysulphide and showed the same tendency to form crystal spots. As nothing but copper sulphide and water can be formed in this reaction, it is evident that neither acids or alkalies are necessary for the formation of these spots.

\section{(d) THE PROTECTIVE COATING}

(1) Relation of Lacquer to Srots.-Experiments with lacquered and unlacquered specimens showed that although certain conditions, such as exposure to sulphur, would cause discoloration of the unlacquered specimens, no crystal spots appeared except on the lacquered specimens. Evidently the presence of a film of lacquer or of some similar material is necessary for the formation of such crystals.

(2) Composition of THE LACQUer.-As the crystals apparently grow between the surface of the sulphide film and the lacquer film (at least initially, although they may penetrate the lacquer film later), it appeared possible that by increasing the adherence of the lacquer the formation of the spots might be retarded or prevented. Over 20 experimental nitrocellulose lacquers were prepared and tried out for this purpose. Although none of these lacquers entirely prevented spotting out, those containing linseed oil showed a marked improvement in this respect. The improvement was most marked in those lacquers containing the highest proportions of linseed oil. Unfortunately, however, lacquers containing linseed oil show a tendency to discolor the finish on both the dark and relieved portions, and hence their use is impracticable.

Preliminary experiments indicated considerable differences in the rate of crystal formation on sulphide finishes lacquered with different types of lacquers. Later in this paper detailed reference is made to

${ }^{6}$ By H. E. Merwin, of the Geophysical Laboratory of the Carnegie Institution. 
more extensive tests on a large number of commercial and experimental lacquers.

(3) Thickness of the Lacquer Film.-Experiments indicated that the thick layers of lacquer produced either by applying two or more coats, or by using less thinner, retard the formation of crystal spots. The rate of formation was retarded by thicker coats of all lacquers tested. For a given type of lacquer the retardation was approximately proportional to the thickness of the film.

(4) Substitutes for Laceuer. - In order to determine whether transparent coatings other than lacquers are beneficial, experiments were made under accelerated conditions with shellac and linseedoil varnish. With the shellac coating, crystal spots were produced as readily as with lacquer. With spar varnish there was little or no formation of crystal spots, but the varnish reacted with the copper sulphide and acquired a green color. It was therefore unsatisfactory.

(5) Sulphide Particles in the Lacquer.-It was suggested that the presence of suspended particles of copper sulphide scraped or washed off of the "oxidized" surfaces during the lacquering might accelerate the spotting. Some of this sulphide was therefore scraped off and mixed with lacquer which was then applied. Portions of the sulphide were also applied to the surface of other specimens whose lacquered film contained no sulphide. After several months' exposure in the absence of any other accelerating agent there was no evidence that the presence of such particles either in the lacquer or in contact with the surface affected the formation of crystals.

(6) Acidity of THE LACQUER.-Following a suggestion that free acid in the lacquer might cause or accelerate the spotting, experiments were made with carefully neutralized lacquers and with lacquers containing appreciable free acid. Lacquers containing free acid tarnish the surface but do not affect the crystal spotting.

(7) Comparison of Lacquers.-Preliminary experiments on the rate of formation of crystal spots under different types of lacquer films led to a more extensive investigation in order that the published results should be representative of the commercially available materials. Manufacturers were invited to submit samples either of their usual make or of experimental lacquers, which were believed to be superior in resistance to penetration by sulphur or moisture. These lacquers were tested with respect to both crystal spotting and to stain spotting. The results of the latter tests are tabulated under Section III of this paper.

The results of the lacquer tests are tabulated without reference to the source of the lacquers, but the firms have been furnished the key numbers of their own samples as a guide to possible improvements. Since it was impracticable to determine the exact composition or reproducibility of any lacquer sample, and it was undesirable to 
report the results by trade or firm name, samples are identified by number, and so far as possible by type, as designated by the makers.

All lacquers were applied by dipping, as this probably represents the simplest and most reproducible procedure, and were tested in the following manner:

Test for crystal spoiting of copper sulphide finishes.-As the results obtained with sheet copper were the same as those with a copperplated surface, the former was used in the tests. Strips of rolled sheet copper-for example, 2.5 by $10 \mathrm{~cm}$ ( 1 by 4 inches)-were given the following treatment. At least 10 specimens were used in each set.

Scrub the surface with powdered pumice and water and rinse in cold water.

Immerse the piece in a warm $\left(105^{\circ} \mathrm{F}\right.$.) solution of potassium polysulphide, prepared by dissolving $3 \mathrm{~g}$ of potassium hydroxide in $100 \mathrm{ml}$ of water, adding $3 \mathrm{~g}$ of flowers of sulphur and boiling for 15 minutes or until the solution assumes a dark-brown color. The solution is then filtered and diluted to 1 liter. The immersion is continued until the surface assumes a uniform black color, usually in one minute.

Scratch brush the surface lightly with a brass wheel and water and rinse and dry.

Dip in lacquer, allow to drain, and apply whatever subsequent treatment, such as baking, is suitable for the lacquer employed. In order to produce lacquer films of approximately the same thickness the lacquer is first diluted with the thinner until it just produces an iridescent film on a dipped metal specimen. Sufficient lacquer is then added to just prevent the formation of iridescence.

Wrap each specimen in high-grade white filter paper, and sprinkle fine flowers of sulphur over the surface of the paper. Store the specimens in a closed vessel; for example, a desiccator, at room temperature $20^{\circ}$ to $30^{\circ} \mathrm{C}$. $\left(68^{\circ}\right.$ to $86^{\circ} \mathrm{F}$.), and examine at intervals; for example, every 24 hours, for two weeks. Record the number, size, and time of appearance of the crystal spots.

The production of lacquer films of approximately equal weight per unit area by the above method was tested by weighing the dried lacquer films. Very nearly the same weight was obtained with all lacquers except No. 4, 12, and 22, films of which weighed approximately one-half as much as the others. This does not mean that these lacquer films were necessarily thinner than the others (with the exception of No. 22, which produced a somewhat iridescent film from the unthinned lacquer as received). Possibly the dried films of some lacquers have lower specific gravities than do the films from other lacquers. No attempt was made to determine these specific gravities.

Twenty specimens consisting of two lots of 10 specimens each were employed in each lacquer test. To minimize the effects of accidental 
conditions which might change from time to time, the two lots of specimens for testing each lacquer were prepared on different days. The results in Table 1 are the average values for both lots. The average values of one lot in the same test did not vary in any case by more than 20 per cent from the average value of the companion lot.

TABLE 1.-Tests of commercial and experimental lacquers for crystal spotting [In contact with sulphur]

GROUP I

\begin{tabular}{|c|c|c|c|c|c|}
\hline \multirow{2}{*}{$\begin{array}{l}\text { Lot } \\
\text { No. }\end{array}$} & \multirow{2}{*}{ Type of lacquer as designated by the maker } & \multicolumn{2}{|c|}{$\begin{array}{l}\text { Temperature of } \\
\text { baking }\end{array}$} & \multirow{2}{*}{$\begin{array}{c}\text { Time } \\
\text { required } \\
\text { to } \\
\text { produce } \\
\text { crystal } \\
\text { spots }\end{array}$} & \multirow{2}{*}{$\begin{array}{l}\text { Time } \\
\text { required } \\
\text { to } \\
\text { produce } \\
\text { crystal } \\
\text { spots } \\
\text { that } \\
\text { cause re- } \\
\text { jection }\end{array}$} \\
\hline & & ${ }^{\circ} \mathrm{C}$. & ${ }^{\circ} \mathrm{F}$. & & \\
\hline $\begin{array}{r}2 \\
6 \\
9 \\
11\end{array}$ & 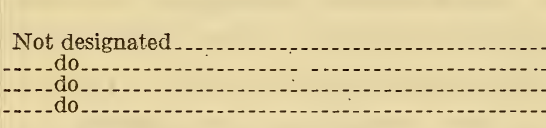 & $\begin{array}{l}50 \\
50 \\
50 \\
50\end{array}$ & $\begin{array}{l}122 \\
122 \\
122 \\
122\end{array}$ & $\begin{array}{r}\text { Hours } \\
84 \\
72 \\
84 \\
36\end{array}$ & $\begin{array}{l}\text { Hours } \\
156 \\
180 \\
156 \\
156\end{array}$ \\
\hline $\begin{array}{r}16 \\
1162 \\
17 \\
19\end{array}$ & $\begin{array}{l}\text { Synthetic resin } \\
\text { Not do designated-a }\end{array}$ & $\begin{array}{l}50 \\
50 \\
50 \\
50\end{array}$ & $\begin{array}{l}122 \\
122 \\
122 \\
122\end{array}$ & $\begin{array}{r}96 \\
156 \\
84 \\
96\end{array}$ & $\begin{array}{l}180 \\
424 \\
180 \\
168\end{array}$ \\
\hline
\end{tabular}

GROUP II

\begin{tabular}{|c|c|c|c|c|c|}
\hline 3 & Nitrocellulose & 50 & 122 & 24 & 72 \\
\hline 4 & Not designated & 50 & 122 & 24 & 60 \\
\hline 5 & 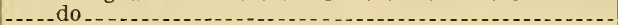 & 50 & 122 & 24 & 48 \\
\hline 7 & Nitrocellulose and natural resin & 50 & 122 & 24 & 60 \\
\hline 8 & Not designated & 50 & 122 & 24 & 48 \\
\hline 10 & Nitrocellulose and gum & 50 & 122 & 24 & 48 \\
\hline 12 & Not designated & 50 & 122 & 24 & 60 \\
\hline $112 \mathrm{a}$ & - & 50 & 122 & 48 & 96 \\
\hline 13 & Natural gum and nitrocollulose & 50 & 122 & 24 & 84 \\
\hline 14 & Synthetic gum & 50 & 122 & 24 & 60 \\
\hline 18 & Not designated. & 50 & 122 & 36 & 72 \\
\hline 20 & 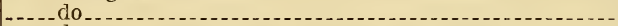 & 50 & 122 & 24 & 60 \\
\hline 21 & $\mathrm{~d}^{2}$ & 50 & 122 & 24 & 72 \\
\hline 23 & 20 & 50 & 122 & 36 & 72 \\
\hline
\end{tabular}

GROUP III

\begin{tabular}{|c|c|c|c|c|c|}
\hline 1 & Phenol-condensation resin & 135 & 275 & 12 & 24 \\
\hline 15 & 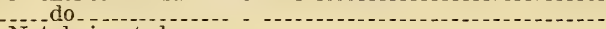 & 1.35 & 275 & 12 & 24 \\
\hline 22 & Not designated & 50 & 122 & 12 & 24 \\
\hline 24 & -....do_. & 135 & 275 & 12 & 24 \\
\hline
\end{tabular}

1 Specimens $12 \mathrm{a}$ and $16 \mathrm{a}$ had thicker lacquer coatings than the others.

The lacquers tested have been divided roughly into three groups. The samples coated with lacquers in Group I were least affected by contact with sulphur. Visible spots did not form until after 72 hours exposure (with the exception of No. 11). The crystal spots did not grow to objectionable size until after 156 hours.

The samples coated with lacquers of Group II are considerably more affected by sulphur than those of Group I. Visible crystal 
spots appear with these lacquers in approximately 24 hours. The spots do not grow as fast as those on specimens coated with Group III lacquers and do not reach the point of rejection until after at least 48 hours.

The samples coated with lacquers in Group III are extremely susceptible to the effects of sulphur as exhibited by the rapid formation of crystal spots. Crystal spots appear visible to the eye on surfaces coated with these lacquers in approximately 12 hours after exposure. Within 24 hours, the spots have grown sufficiently in size and number to cause rejection of the specimen.

The ratio of the time for the first appearance of the crystal spots to that necessary for sufficient growth to cause rejection of the specimens was (with the exception of lacquer No. 11), between 1 to 2 and 1 to 3 , thus showing a general parallelism between the two stages of failure.

Two types of crystal growth were noted. With lacquers of Groups II and III, with one or two exceptions, the crystal spots grew beneath the lacquer film and could not be removed by rubbing the surface. The crystal spots with lacquers of Group I, however, while they initially grew beneath the lacquer, tended to penetrate the film after a short period of growth. At the end of the run the crystal spots had penetrated the lacquer to such an extent that they could be almost entirely removed by rubbing the surface. In general, the crystal spots were much smaller on specimens coated with Group I lacquers than those coated with Group II and III lacquers.

In order to amplify the preliminary experiments on the effect of increasing the thickness of the lacquer film on the rate of crystal growth, the films of lacquer No. 12 (Group II) and No. 16 (Group I) were increased to about 250 per cent of their previous thickness by applying a single coat of a less diluted lacquer. It will be noted from the results of these tests (12a and $16 \mathrm{a}$ in Table 1 ) that an increase in the thickness of the lacquer film produced an approximately proportional increase in the time required for the appearance and growth of the crystals.

- In connection with the above tests, strips of bright copper were coated with the same lacquers and were kept in contact with sulphur for from four to six weeks. During this period practically no tarnish appeared on any of the specimens, although unlacquered copper strips turned dark in a few days under these conditions. Evidently none of these lacquers permit much sulphur to pass through. These results show that there is no necessary relation between the permeability of a lacquer to sulphur and its ability to retard the formation of the crystal spots.

(8) Effect of a Film Superimposed on the Lacquer.-Experiments proved that a grease film, applied to the lacquered surface by 
dipping the articles in a dilute solution-for example, 4 per cent or less of petrolatum in carbon tetrachloride-retards the formation of crystal spots in the presence of sulphur. Crystal spots formed on ungreased specimens in contact with sulphur within 1 to 4 days, whereas spots did not appear on specimens with the petrolatum film until after 10 to 13 days. Since the preliminary announcement of the above procedure it has been reported that in one plant a paraffin oil has been successfully employed as a protective film on lacquered oxidized finishes.

\section{(e) THE ENVIRONMENT}

(1) Sulphur.-Contact with sulphur is the most rapid means of accelerating the formation of crystal spots. If the surfaces are sprinkled with flowers of sulphur, spotting usually occurs within 1 to 4 days. Even in this case, however, it is probably the sulphur vapor produced by the very slow evaporation of the sulphur that causes the spots. Experiments with lump sulphur contained in the same vessel with the specimens but not in contact with them showed that it also accelerates spotting, but not nearly so rapidly as does the fine sulphur. (Lump sulphur may require as much as 40 to 50 days to cause spotting.) It is also possible that the sulphur dissolves in the lacquer film and thus passes through it.

(2) RUBBER.-Rubber usually contains free sulphur, and in these tests it was found to produce the spots as readily as does powdered sulphur. That the effect of ordinary rubber is due principally to the presence of free sulphur on the surface and its evaporation is evident from some experiments with a special "nonblooming" rubber that contains little or no free sulphur. It was found that with the nonblooming rubber only about one-third as much spotting is produced as with ordinary rubber.

(3) Sulphur Compounds.--Experiments with air containing from 0.1 to 1.0 per cent by volume of hydrogen sulphide showed that with even the lowest concentration crystal spots occur, but not so rapidly as with free sulphur. The hydrogen sulphide also causes tarnish. Air containing 1 per cent of sulphur dioxide causes rapid tarnish of . the specimens but no formation of crystal spots.

(4) Wrapping Materials.-Extensive experiments have shown that the spotting may be accelerated by contact with certain papers, such as kraft papers or cardboard boxes, employed in wrapping or storing the specimens. Actual contact with the paper appears necessary to produce the spotting. Thus, when groups of two or more specimens, so wrapped that the paper came in contact with only one side of each plate, were stored in a closed desiccator containing only these specimens crystal spots appeared solely on the side of the plate in contact with the paper. It is difficult, however, to show a 
direct relation between the sulphur content of the paper and the effect on spotting. Filter paper with only 0.0007 per cent of sulphur caused about as much spotting as kraft paper with 0.002 to 0.003 per cent or cellophane with 0.005 per cent of sulphur. It is equally difficult to attribute the spotting to any constituent of the paper other than the sulphur. In addition, paper does not produce spotting quantitatively. Thus, while all specimens of the same lot of sulphide finishes in contact with sulphur will spot at very nearly the same rate, only part of the specimens will spot at all when wrapped in paper. It is quite possible that the sulphur present in paper may be localized and, hence, produce spotting only on specimens or portions of them that are adjacent to high concentrations of sulphur in the paper.

Determination of sulphur in paper.-The various methods that have been used or suggested for detecting or determining sulphur in paper all relate to the sulphur which is present as sulphide or in some form that may evolve hydrogen sulphide under certain conditions. Inert substances, such as calcium sulphate, that may be used as fillers are not included in the determination of sulphur as conducted for this purpose. Among the methods suggested are $(a)$ wrapping polished silver in the moistened paper and determining the extent of the tarnish; (b) heating the paper with zinc and hydrochloric acid, bringing the evolved hydrogen sulphide in contact with moist lead acetate paper, and noting the color produced; and (c) treating the paper with zinc and hydrochloric acid, passing the gases into an alkaline cadmium solution, and titrating the hydrogen sulphide by the method used in determining "evolution sulphur" in steel. Of these $(b)$ was found most promising for our purposes. Method (a), while undoubtedly a valuable practical method for detecting some minimum amount of sulphur, does not give quantitative values. Method $(c)$ is difficult to apply with small samples of paper, and with large samples it is difficult to expel all the sulphur. The following method is based upon the "official paper testing methods of the pulp and paper industry," and upon modifications suggested in a personal communication from B. Egeberg, of the International Silver Co.

Apparatus.-The special apparatus required for this determination consists of a $500 \mathrm{ml}$ round-bottom flask having the connections and dimensions shown in Figure 3. All gases generated in the flask pass through a filter paper which is clamped between the mouth of the flask and the end of the tube.

Specimen.-The specimen consists of 0.25 to $1.0 \mathrm{~g}$ of paper (depending on the sulphur content) either ground or thoroughly disintegrated by shaking with distilled water.

Reagents.-Small pieces of C. P. stick zinc free from sulphur and arsenic are activated by adding $10 \mathrm{ml}$ of a solution containing $1 \mathrm{~g} / \mathrm{l}$ of $\mathrm{CuSO}_{4} .5 \mathrm{H}_{2} \mathrm{O}$ (or $0.25 \mathrm{~g} / \mathrm{l}$ of copper) to each gram of zinc. After allow- 
ing the solution to stand a few minutes for the deposition of the copper, wash the zinc with distilled water until free from zinc sulphate. The zinc can be reactivated several times.

Concentrated C. P. hydrochloric acid free from sulphur and arsenic.

C. $\mathrm{P}$. lead acetate, $100 \mathrm{~g} / \mathrm{l}$ of $\mathrm{Pb}\left(\mathrm{C}_{2} \mathrm{H}_{3} \mathrm{O}_{2}\right)_{2} \cdot 3 \mathrm{H}_{2} \mathrm{O}$.

C. P. sodium thiosulphate solution, containing $3.9 \mathrm{mg} / \mathrm{l}$ of $\mathrm{Na}_{2} \mathrm{~S}_{2} \mathrm{O}_{3}$. $5 \mathrm{H}_{2} \mathrm{O}$. Each milliliter of this solution contains $0.001 \mathrm{mg}$ of sulphur,

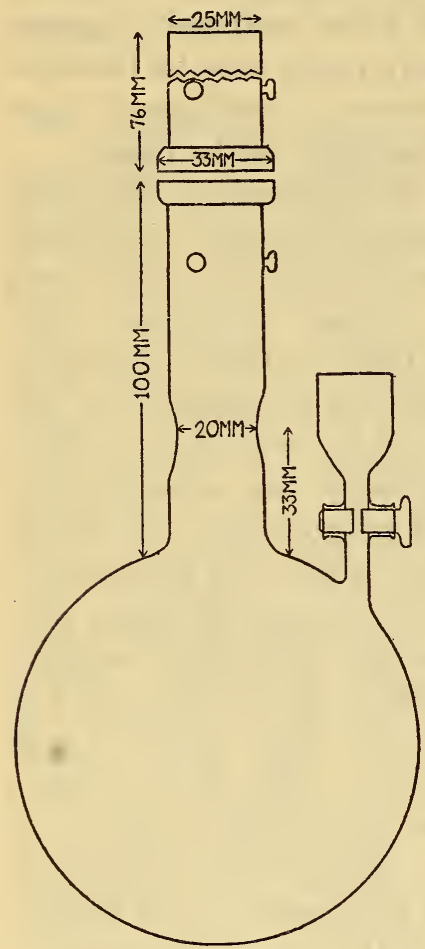

Figure 3.-Apparatus for the determination of sulphur in paper all of which is evolved as hydrogen sulphide. This is equivalent to 0.0001 per cent of sulphur in a $1 \mathrm{~g}$ sample.

Sulphur-free cotton, prepared by boiling surgical absorbent cotton in a dilute solution of sodium hydroxide and washing thoroughly with distilled water.

Transfer the weighed specimen to the flask with $80 \mathrm{ml}$ of distilled water and add approximately $2 \mathrm{~g}$ of activated zinc. Insert in the neck of the flask at the constriction a loose wad of surgical absorbent cotton. Clamp between the mouth of the flask and the tube a hardened filter paper (such as Schleicher and Schüll's 575) which has been freshly moistened with a 10 per cent solution of lead acetate. Rubber bands may be employed for clamping the filter paper into place between the tube and neck of the flask without danger of contamination if sufficient care is taken. Place another wad of absorbent cotton in the tube above the filter paper. Prepare flasks under duplicate conditions containing in place of the paper under test pure sulphur-free cotton and measured amounts of sodium thiosulphate solution. Add to each flask $20 \mathrm{ml}$ of concentrated hydrochloric acid and set all the flasks on the steam bath. At intervals of 15 minutes remove them to a hot plate and heat the solution to the boiling point until moisture just begins to condense in the neck of the flask beneath the cotton plug. Return to the steam bath, and after 15 minutes repeat the boiling on the hot plate. After three such treatments, requiring a total of about 50 minutes, replace the lead acetate paper with a fresh piece and repeat the heating and boiling. If, as is usually the case, no stain is produced on the second paper, the color of the first paper serves to measure the sulphur content of the sample. If the second paper is darkened, 
it is better to start a fresh determination, using a smaller sample, in order that all the sulphur may be evolved in a convenient period. The percentage of sulphur present is found by comparing the depth of the color developed by the sulphur from the specimen with that developed from known amounts of sulphur evolved from the thiosulphate solutions. Blanks on the reagents should accompany every determination.

As $0.000001 \mathrm{~g}$ of sulphur will give a distinct stain, care must be taken to protect the paper under test from contamination. It must be protected from atmospheric fumes and should not be handled with bare hands. The evolution of hydrogen is insufficient to completely remove the hydrogen sulphide from the flask; hence it is necessary to heat the contents of the flask to the boiling point for short periods. More concordant results were obtained by this procedure than by simply warming the flask. Very pure zinc at times reacts rather slowly with dilute hydrochloric acid even after activating with copper. It is possible to hasten the reaction by employing platinum wire in contact with the zinc as an additional activating agent.

The following table contains the average results, obtained in several determinations by the above method, of the active sulphur content of samples of typical materials which have been or might be employed for wrapping hardware:

TABLE 2.-Active sulphur content of wrapping materials

\begin{tabular}{|c|c|}
\hline Materials & $\begin{array}{l}\text { Active } \\
\text { sulphur }\end{array}$ \\
\hline 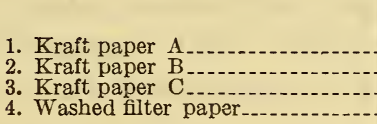 & $\begin{array}{c}\text { Per cent } \\
0.0025 \\
.0020 \\
.0030 \\
.0007\end{array}$ \\
\hline 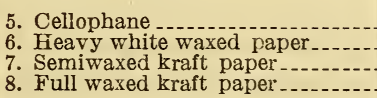 & $\begin{array}{l}.0050 \\
.0012 \\
.0027 \\
.0020\end{array}$ \\
\hline
\end{tabular}

Experiments were made upon the use of wax paper and tin foil as substitutes for kraft paper. The use of waxed papers is not original but was suggested by the experience of several plants. The effect of petrolatum films was also included in these tests.

Seventy specimens of sulphide finishes were exposed wrapped in waxed paper and divided into two portions-one lot in an atmosphere approaching 90 per cent humidity in closed desiccators and the other lot under uncontrolled humidity conditions but stored where there was no danger of contamination from sulphur. At the same time

${ }^{7}$ Communicated by R. E. Hicks, E. G. Anderson, and others. 
approximately the same number of specimens were stored under the same conditions wrapped in kraft papers, containing 0.002 to 0.003 per cent of active sulphur. As there were no other possible sources of sulphur, all spotting that occurred must have been due to the effect of the papers. A number of articles wrapped in tin foil were also exposed under these conditions at the same time. To test the efficacy of a superimposed film on the lacquer for the prevention of crystal spots, approximately 50 specimens of sulphide finishes were dipped in a 4 per cent solution of petrolatum in C. P. carbon tetrachloride. The surface was then wiped, leaving a transparent film of petrolatum on the lacquered surface. These specimens were then wrapped in kraft paper similar to that employed for wrapping other specimens and exposed under the same conditions and at the same time as the other specimens. The results are shown in Table 3.

TABLE 3.-Crystal spotting of specimens wrapped with various materials

[Results after nine months' exposure]

\begin{tabular}{|c|c|c|c|c|}
\hline Material employed for wrapping & Humid- & $\begin{array}{c}\text { Speci- } \\
\text { mens } \\
\text { heavily } \\
\text { spotted }\end{array}$ & $\begin{array}{c}\text { Speci- } \\
\text { mens } \\
\text { lightly } \\
\text { spotted }\end{array}$ & $\begin{array}{l}\text { Speci- } \\
\text { mens un- } \\
\text { spotted }\end{array}$ \\
\hline $\begin{array}{l}\text { Kraft paper } \\
\text { Do } \\
\text { Waxed paper } \\
\text { Do } \\
\text { Petrolatum film and kraft paper. } \\
\text { Do } \\
\text { Tin foil } \\
\text { Do }\end{array}$ & $\begin{array}{r}\text { Per cent } \\
90 \\
30-70 \\
90 \\
30-70 \\
90 \\
30-70 \\
90 \\
30-70\end{array}$ & $\begin{array}{r}\text { Per cent } \\
16 \\
15 \\
1 \\
1\end{array}$ & $\begin{array}{r}\text { Per cent } \\
14 \\
21\end{array}$ & $\begin{array}{r}\text { Per cent } \\
70 \\
64 \\
100 \\
99 \\
100 \\
100 \\
100 \\
100\end{array}$ \\
\hline
\end{tabular}

By the term "heavily spotted" is meant that the specimens were unfit for commercial use and by "lightly spotted" that only few and small spots were present, which did not unfit the specimen for commercial use.

These results show clearly that wax paper and tin foil are superior to kraft paper. When the latter is used, a petrolatum film is advantageous.

The spots appeared at widely different intervals on the specimens wrapped in kraft paper. Of those specimens which failed spots appeared on about 25 per cent within two weeks, on an additional 40 per cent within six weeks, and on most of the others within three months. The above table also confirms the conclusion (par. 6) that the humidity has no effect upon the rate of spotting.

(5) Temperature.-Specimens of sulphide finishes in contact with sulphur or rubber were kept at temperatures of $0^{\circ}$ to $5^{\circ} \mathrm{C}$. $\left(32^{\circ}\right.$ to $41^{\circ} \mathrm{F}$. $) ; 22^{\circ}$ to $27^{\circ} \mathrm{C}$. $\left(72^{\circ}\right.$ to $81^{\circ} \mathrm{F}$.) and $40^{\circ}$ to $50^{\circ} \mathrm{C}$. $\left(104^{\circ}\right.$ to $113^{\circ} \mathrm{F}$.), respectively. Very large crystal spots appeared within 12 hours after exposure at the highest temperature; smaller crystal 
spots appeared within 2 to 4 days on specimens exposed to room temperatures and within 5 to 7 days on specimens exposed to low temperatures. It is evident from these results that an increase in temperature accelerates the formation of crystal spots on finishes in contact with sulphur. The effect of an increase in temperature may be due to an increase in the vapor pressure of the sulphur, and therefore in its content in the atmosphere, to the acceleration of the process of forming or recrystallizing the copper sulphide, or to an increase in the solubility of sulphur in the lacquer.

(6) Humidity.-As it was commonly believed that high humidity is partly responsible for the formation of these crystal spots, the effect of humidity was determined. The specimens were kept in desiccators with humidities controlled by the concentration of the sulphuric acid present. Samples kept in an atmosphere approaching 90 per cent humidity without any rubber, sulphur, paper, or other accelerating agent present showed at the end of eight months very few spots. It is evident, therefore, that moisture alone does not cause this type of spotting.

When specimens, together with sulphur or rubber, were kept in vessels in atmospheres with zero, 20,55 , and 90 per cent humidities, respectively, the spotting occurred to an equal extent. It is evident, therefore, that the action of the sulphur is not appreciably affected by the humidity.

Specimens wrapped in various kinds of paper were subjected to similar variations in humidity. No differences in the spotting were observed except with cellophane paper which contains more sulphur (0.005 per cent) than any of the other papers used. With this paper a high humidity appeared to increase the tendency toward spotting and also caused tarnishing.

(7) EFfeCt of OXYGen.-As spots formed occasionally though slowly when no sulphur, rubber, or paper was known to be present, it was thought that the oxygen of the air might contribute to their formation. The fact that on specimens kept in a vacuum in contact with sulphur for 75 days no spots appeared, although tarnishing occurred, seemed to confirm the view that oxygen is necessary. When, however, other specimens and sulphur were kept in pure oxygen and oxygen-free nitrogen, respectively, spotting occurred to an equal extent in each. This shows that oxygen is not necessary and leaves unexplained the results obtained in a vacuum.

\section{PLANT TESTS}

The elimination of free sulphur or hydrogen sulphide from the atmosphere in contact with the finishes is largely a matter of control of conditions in storage and transit. Sulphur or hydrogen sulphide in the plant atmosphere may come from sulphur-melting furnaces or 
from the gases from other types of furnaces. Several, well authenticated instances of difficulties arising from vapors from sulphurmelting furnaces being carried to the parts of the plant where sulphide finishes were prepared or stored have been reported. This difficulty was, of course, easily overcome when the source of the trouble was realized.

The danger of the former custom of clipping the wrapped sulphide finishes with rubber bands has been realized, and the practice has been discontinued in a majority of the plants. That such a custom has not been entirely discontinued was emphasized within the past year by the receipt of a shipment of sulphide finishes for experimental purposes clipped with rubber bands and hence spotted when received.

During transit sulphur may come in contact with the finishes in a variety of ways. The danger is especially great during shipments through the Tropics, where the articles may be stored in the hold of steamships and subjected to sulphur gases from coal bunkers and to elevated temperatures. It is obvious that contact with sulphur gases under such conditions might be obviated by shipment in sealed metallic containers if the difficulty experienced warranted theincreased expense.

Tests of promising remedies, such as the use of waxed paper and a petrolatum film, were made in four different plants where crystal spotting had been occasionally reported. Approximately 1,000 specimens of oxidized finishes, mainly brass, bronze, and copper-plated steel escutcheon plates, were stored in the four plants under conditions reported to cause spotting. Portions of the lots were wrapped in kraft papers containing the same percentage of sulphur as those employed in laboratory tests and in waxed papers. Others were given a film coating by dipping into a 4 per cent solution of petrolatum in carbon tetrachloride and wiped. The petrolatum film did not discolor or disfigure the specimens. No crystal spotting occurred on any of the specimens after exposures of 8 to 11 months.

Inconclusive results were also obtained from shipments sent out and returned to the plants. One lot of approximately 150 specimens was shipped from Connecticut to Chicago by train and returned after seven months. Another shipment was sent by boat to Australia and returned to this country after seven months. This latter shipment was placed in the hold of the boat in a position neither particularly favorable nor detrimental in respect to sulphur gases. Part of this shipment was placed in hermetically sealed metal boxes instead of the usual wooden packing cases. None of the specimens in any of the shipments showed any crystal spotting. The results of these plant tests indicate the difficulty of obtaining definite results under plant conditions with this type of spotting. They at least indicate that the crystal spotting is much more irregular in occurrence and more 
subject to variable conditions of transit and storage than is stain spotting. (No such difficulty was found in obtaining plentiful and definite evidence of the latter in similar plant tests.) It is believed that the following conclusions of the laboratory tests are valid, even though they have not yet been fully confirmed in plant practice. Certainly, whenever plant conditions are such as to cause crystal spotting, the procedures here suggested warrant consideration and trial.

\section{CONCLUSIONS}

1. Crystal spots appear in the form of dendritic (treelike) crystals on the metal finishes containing copper sulphide, silver sulphide, or nickel sulphide and which are subsequently lacquered.

2. Crystals of the same general structure are encountered in nature under similar conditions of growth; that is, between two planes pressed closely together. Magnetite crystals often grow between flakes of mica.

3. The common crystal spots and the copper sulphide on which they occur both consist of cuprous sulphide, $\mathrm{Cu}_{2} \mathrm{~S}$, with the $\mathrm{X}$-ray pattern of the mineral chalcocite.

4. The crystals of cuprous sulphide may conceivably be formed either by a recrystallization of the much finer (but also crystalline) coating produced by the action of polysulphide solutions on copper, or by the formation of new copper sulphide by the slow action of sulphur upon minute areas of copper exposed through the original sulphide film. In the former case the presence of minute amounts of sulphur might simply accelerate the formation of the crystals by a process of recrystallization.

5. The composition of the base metal underlying the coating of copper or brass has no influence on the growth of the crystal spots.

6. Previous treatment of the metal with acids or alkalies does not affect the growth of the crystal spots.

7. The only substance found to accelerate the growth of crystal spots is sulphur, either as free sulphur or as hydrogen sulphide. These may be introduced into the atmosphere either directly or from rubber or paper employed in wrapping the sulphide finishes.

8. An increase in temperature increases the rate of growth of crystal spots in the presence of sulphur.

9. The growth of crystal spots on lacquered sulphide finishes in the presence of sulphur may be retarded by certain types of commercial lacquers. About one-third of the lacquers examined showed distinct value in this respect.

10. An increase in the thickness of the lacquer retards the growth of crystal spots.

11. The employment of waxed papers, in which the sulphur has been rendered inactive by paraffin and which are less permeable 
to sulphur vapor or hydrogen sulphide, retards the growth of crystal spots on sulphide finishes.

12. A transparent film of grease or oil on the lacquer film retards the growth of crystal spots in the presence of sulphur.

\section{STAIN SPOTTING}

\section{OCCURRENCE AND COMPOSITION OF STAIN SPOTS}

It is common knowledge in the plating industry that far more difficulty is experienced with stain spotting than with the crystal spotting described in the preceding section. The importance of stain spotting is also indicated by the frequent published references to it, especially in the trade publications. Few researches have been conducted upon this subject, and most of the articles, some of which are anonymous, consist of statements regarding its occurrence and possible remedies without giving quantitative data. It is hard, therefore, to judge from such papers the efficacy of the proposed remedies.

In one of the earliest articles ${ }^{8}$ it was pointed out that these spots are caused by porosity of the castings and by absorption of liquids in them. Rinsing alternately in hot and cold water was one of the remedies suggested. In an editorial following the above paper the use of sodium salts instead of the more deliquescent potassium salts was suggested.

In the following year ${ }^{9}$ suggested remedies included soaking in fish-oil soap, nickel plating before plating with copper or brass, allowing the plated castings to stand and spot out before finishing, and baking after plating. Somewhat later ${ }^{10}$ the presence of blisters in the copper deposits was suggested as the cause of spotting.

G. B. Hogaboom on two occasions ${ }^{11}$ attributed the spotting to the presence of acid or alkaline materials in the pores and concluded that none of the remedies thus far proposed had proven entirely effective. In fact, he listed this as one of the "unsolved problems in electroplating."

C. F. Burgess and L. T. Richardson ${ }^{12}$ studied spotting out on silver plating and concluded that sodium cyanide is more deliquescent than potassium cyanide, and the latter should, therefore, be used.

C. H. Proctor ${ }^{13}$ recommended as remedies alternate treatment with hot and cold water and also wrapping in wax paper to exclude moisture.

${ }^{8}$ Anonymous, Brass World, 2, p. 369; 1906.

${ }^{2}$ Anonymous, Brass World, 3, p. 65; 1907.

10 Anonymous, Brass World, 5, p. 429; 1909.

11 Trans. Am. Electrochem. Soc., 19, p. 53; 1911; 29, p. 376; 1916

12 Metal Ind., 11, pp. 477 and 508; 1913.

13 Metal Ind., 12, p. 281; 1914. 
Remedies suggested by F. Ottman ${ }^{14}$ included boiling in cream of tartar solution and dipping in nickel or acid copper solutions in order to neutralize alkalis in the pores.

R. M. Goodsell ${ }^{15}$ advocated as remedies the presence of sufficient free cyanide in the plating bath, thorough rinsing, baking before lacquering, and the application of the water-dip lacquer when the articles are cold.

In a more recent article C. H. Proctor ${ }^{16}$ advised the maintenance of a low content of free cyanide in the plating solution, rinsing in hot and cold water, baking at $212^{\circ} \mathrm{F}$. $\left(100^{\circ} \mathrm{C}\right.$.), and the application of water-dip lacquers at a temperature of $120^{\circ} \mathrm{F} .\left(49^{\circ} \mathrm{C}\right.$.).

A. K. Graham ${ }^{17}$ found that the pores are not necessarily present in the original castings but may be caused by the attack of cleaning or pickling solutions upon segregated impurities in the castings. $\mathrm{He}$ therefore emphasized the importance of producing castings that are free not only of pores but also of segregations.

From a study of the literature and from preliminary observations in plants and in the laboratory the following tentative conclusions were reached regarding the occurrence, cause, and nature of stain spots:

1. Stain spots may occur on either oxidized or unoxidized finishes.

2. Stain spots occur on both lacquered and unlacquered specimens, while crystal spots occur only on lacquered objects.

3. Stain spots occur on both plated and unplated castings.

4. Moisture in the surrounding atmosphere is necessary to produce stain spots. Specimens that were exposed for several weeks at zero humidity without staining spotted badly in a few hours upon removal to an atmosphere with high humidity.

5. Stain spots usually occur in a humid atmosphere in a few hours, while crystal spots may not appear under normal conditions of storage until weeks or months after finishing.

6. Stain spots are associated with pores in the casting, either present originally or produced by the action of various solutions. This conclusion is drawn from the frequent presence of a small dark spot in the center of each stain and from the fact that in many cases stains reappear at the same points when the stained specimens are stripped and polished to a new metal surface and then replated and refinished. The stains frequently reappear at the same points after two or more refinishing operations. These observations confirm those made by A. K. Graham and others.

14 Metal Ind., 14, p. 153; 1916.

${ }_{15}$ Month. Rev. Am. Electroplaters' Soc., 12, p. 16; Sept. 1, 1925.

16 Metal Ind., 24, p. 370; 1926.

${ }_{17}$ Month. Rev. Am. Electroplaters' Soc., 14, p. 4; March, 1927 
7. The stains involve the presence of "hygroscopic" (moisture absorbing) compounds occluded or formed in the pores of the metal by the action of cleaning, plating, or coloring solutions.

8. Either alkaline or acid compounds may cause stain spotting. Alkaline materials are, however, more likely to be retained in the pores, even when both acid and alkaline solutions have been applied to the metals. Definite evidence of this was furnished by the fact that the phenol-condensation lacquers subsequently applied are turned pink adjacent to the spots. This reaction is characteristic of the action of alkalis on phenol-condensation products.

9. Moisture in the atmosphere absorbed by salts in the pores of a metal may cause the salts to "creep" out over the surface, producing a stain and in extreme cases a crystallization of solid material on the surface of the object within the area of the stain.

10. It is also possible for stains to form on metals which are not porous by the evaporation on their surface of contaminated rinse waters, leaving compounds which attack and discolor the surface. As this type of spotting can be completely and conveniently prevented by more thorough rinsing in clean water, no actual investigation of other remedies was necessary.

\section{FACTORS INVOLVED}

\section{(a) METHOD OF TEST EMPLOYED}

In order to obtain comparative results within short periods, an accelerated test for stain spots was employed. This consisted simply in exposing the articles at $20^{\circ}$ to $30^{\circ} \mathrm{C}$. $\left(68^{\circ}\right.$ to $86^{\circ} \mathrm{F}$.) to a high humidity (90 to 100 per cent) in a closed vessel containing water. Under such conditions the stain spotting usually appears in a relatively short time.

\section{(b) THE BASE METAL}

If porosity of the base metal is responsible for the retention of solutions and their subsequent staining of the surface, the most obvious remedy would be to employ only castings free from pores. It is at least possible that less porous castings might be made by changing the foundry conditions, such as the composition or temperature of the molten metal, the design of the patterns, or the character of the molds. Experimental work upon such possibilities must be conducted in a foundry, as it is difficult to reproduce foundry conditions in small-scale laboratory experiments. That such possibilities at least deserve investigation is indicated by the experience of one plant. A simple change in the design of a cast-iron flush-bolt case, resulting in a thicker average cross section, made a marked decrease in the tendency to spot. Laboratory tests on these products showed that, after being brass plated and lacquered, 100 per cent of 
the thin-walled samples failed in the humidity test and only 15 per cent of the thick-walled. Similar differences were observed in plant experience with these products. Metallographic cross sections of the two products failed, however, to show any significant difference in the structure or porosity of the castings. This subject needs further study.

When it is not feasible to change the pattern, it is sometimes possible to select a less porous metal. Thus, in one plant the spotting was overcome by substituting rolled steel for malleable iron in lock fronts that were subsequently brass plated.

(c) CLEANING AND PLATING PROCESSES

If, as was indicated by the preliminary studies, alkaline solutions are most likely to be absorbed and retained in the pores, it would naturally be desirable to eliminate such materials from the process. Actually, however, alkaline solutions, such as those of sodium hydroxide, carbonate, and phosphate, are commonly used for cleaning metals to remove grease and similar foreign materials, and alkaline cyanide copper and brass solutions are used in most of the plating processes. It is not feasible to substitute other methods or materials for the alkaline cleaning operations. Scrubbing with pumice or similar materials may completely remove grease but is expensive and inconvenient. On iron and steel acid copper solutions can not be used directly for plating, and there is no practical acid brass plating solution. It is obvious, therefore, that for most purposes alkaline solutions will be found necessary. When brass parts are copper plated for subsequent "oxidizing" with polysulphides, acid copper baths may be substituted for the cyanide copper commonly used. It is also possible to use instead of potassium or sodium polysulphide a solution of ammonium polysulphide, which is less likely to leave nonvolatile alkaline compounds in the pores.

In order to determine whether by elimination of sodium or potassium salts, the stain spotting can be reduced, the following experiments were made. A number (lot 1) of cast brass and bronze parts were cleaned electrolytically in an alkaline solution, plated in a copper cyanide solution, colored with potassium polysulphide, and lacquered. Others (lot 2) of the specimens were cleaned by pumice scrubbing, plated in an acid copper bath, colored with ammonium polysulphide, and lacquered. The specimens were then placed in the humidity chamber. Within 12 hours 68 per cent of lot 1 were badly spotted, and at the end of 63 days only 8 per cent were unspotted. Of lot 2 , 16 per cent spotted badly in from 1 to 7 days, but at the end of 63 days the remaining 84 per cent were unspotted. No similar improvement was noted when electrolytic cleaning instead of pumice scrubbing was used in the procedure employed for lot 2. Evidently, 
therefore, introduction into a strong alkaline solution at any stage is detrimental. The concentration of alkali in the polysulphide solutions used for coloring (less than $0.05 \mathrm{~N}$ ) is small, and no detectable effect was obtained by substituting ammonium polysulphide for the potassium compound.

In finishing certain classes of work, especially solid brass or bronze, it is sometimes possible to obtain the desired appearance by means of "greaseless polishing compounds." Their use eliminates the necessity of subsequent washing or cleaning processes to remove grease and abrasives left from the polishing operation. This procedure avoids the possibility of alkaline liquids entering the pores and producing spots.

\section{(d) REMOVAL OR EXCLUSION OF COMPOUNDS FROM THE PORES}

The permanent presence of the objectionable alkaline salts in the pores might be prevented by excluding, neutralizing, or removing them.

Attempts to first fill the pores with some viscous inert substance, such as glycerin or lacquer, that might prevent access of the alkaline cleaning or plating solutions into the pores were unsuccessful. Attempts to first fill the pores with a neutral or acid solution were also unsuccessful. Plating in a nickel bath before introducing into any alkaline solution produced no improvement. Boiling gray-iron castings with dilute chromic acid $\left(25 \mathrm{~g} / \mathrm{l}\right.$ or $3.3 \mathrm{oz} . / \mathrm{gal}$., $\mathrm{CrO}_{3}$ ) before cleaning or plating was also ineffective.

Treatment of the plated castings with acid solutions, such as acetic acid (50 g/l or $6.7 \mathrm{oz} . / \mathrm{gal}$.$) , chromic acid ( 25 \mathrm{~g} / 1$ or $3.3 \mathrm{oz} . / \mathrm{gal}$.$) ,$ hydrochloric, sulphuric, or nitric acid (30 g/1 or $4 \mathrm{oz} . / \mathrm{gal}$.$) , and cream$ of tartar ( $6 \mathrm{~g} / \mathrm{l}$ or $0.8 \mathrm{oz}$./gal.), each followed by thorough rinsing, all failed to prevent the subsequent spotting. Actually many of these acid rinses attacked and discolored the plated coatings.

Extended rinsing with either hot or cold water or alternately with hot and cold water had no appreciable effect on the spotting. All these experiences indicate that the pores in the metal must be very fine capillaries, and also that alkaline solutions are much more strongly held in such pores than are acid solutions.

Baking the plated parts to about $225^{\circ} \mathrm{F}$. $\left(107^{\circ} \mathrm{C}\right.$.) before lacquering dehydrates any compounds in the pores and retards the tendency to spot. This procedure is not applicable, however, in many plant procedures or to metals with a sulphide finish, which discolors at temperatures above about $60^{\circ} \mathrm{C}$. $\left(140^{\circ} \mathrm{F}\right.$.).

No improvement was obtained by plating with thicker deposits or by plating with several coats of copper or brass. It is evident, therefore, that the pores are not filled up or sealed up by metal. 
Mechanical operations, such as burnishing and tumbling after plating, were found to produce a slight improvement, which indicates that some of the pores were at least partially sealed up. This procedure is not, however, applicable to all products.

The only practicable method of reducing the concentration of the deliquescent alkaline compounds in the pores is to expose the articles to a high humidity for 12 to 24 hours, under which conditions a large part of the salts exude, and; of course, produce stains on the surface. These can then be removed by scratch brushing or buffing and the articles finished and lacquered. Even this procedure is not effective if the castings are very porous. It is, however, valuable in decreasing the content in the pores of alkali which may subsequently absorb moisture and attack the lacquer. Thus, in one series of experiments it was found that such preliminary spotting increased from 5 to 25 per cent the proportion of unstained castings that were subsequently coated with a poor lacquer. With similar specimens from the same lot of castings coated with two better lacquers the preliminary spotting increased the yield of unspotted samples from 70 to 100 per cent and 45 to 75 per cent, respectively.

(e) THE PROTECTIVE COATING

If it were feasible to keep the finished articles in a practically dry atmosphere, no stain spotting would occur. This is, of course, not practicable, though it is often possible to avoid storage of such products in rooms with high humidity.

It is necessary, therefore, to depend upon a coating, such as lacquer, to prevent access of moisture. Preliminary experiments showed that phenol-condensation lacquers were more efficient in preventing stain spotting than were the average nitrocellulose lacquers. Thus, with brass and bronze castings from the same lot that had been copper plated in a copper cyanide solution and colored with polysulphides, phenol lacquers prevented any spotting within two weeks, while with one nitrocellulose lacquer 75 per cent were spotted and with another 25 per cent. Very similar ratios were obtained with these lacquers on brass-plated gray iron and malleable iron castings. As it was known from previous studies on the waterproofing properties of lacquers that the phenol products were relatively impervious to moisture, their value against stain spotting was naturally attributed to this property. The relative permeabilities of different lacquer films to moisture were determined by the following method, which is based on that described by P. H. Walker and E. F. Hickson ${ }^{18}$ for testing paint coatings:

A circular hole about $5 \mathrm{~cm}$ ( 2 inches) in diameter was cut in the cover of a tinned iron box (a common ointment box) and a piece of

18 B. S. Jour. Research, 1 (RP1), p. 1; 1928. 
100-mesh copper gauze was soldered across the opening. To this gauze were then applied several coats of the lacquer to be tested until a definite increase in weight, corresponding to an arbitrary film thickness, was obtained. Each coat was dried by the method adapted to the lacquer used. The cover was then put on the box in which had been placed about $5 \mathrm{~g}$ of anhydrous calcium chloride. The joint was sealed with paraffin and the box was weighed, placed in the high humidity chamber, and reweighed at intervals. The gain in weight indicated the permeability of the lacquer to water vapor. Blank tests were also run without any calcium chloride in the box to measure the tendency of the lacquer to adsorb moisture. The freedom of the films from microscopic pores was proven by testing their resistance to the passage of air when the pressure was reduced on one side.

These tests (reported in Table 4) showed conclusively that the phenol-condensation lacquers, which are very effective against stain spotting, are more impervious to moisture than are nitrocellulose lacquers. (The phenol lacquers, however, adsorb more moisture than the nitrocellulose.) When the same test was applied to different lacquers containing nitrocellulose, it was found that some samples which are relatively permeable to moisture, exert more protection against stain spotting than other samples with lower moisture permeability. This is illustrated in Table 4 in which the lacquers have the same numbers as in Table 5.

Table 4.-Permeability of lacquer films to moisture

[Exposed to high humidity at about $25^{\circ} \mathrm{C}$. $\left(77^{\circ} \mathrm{F}\right.$.) for 14 days]

\begin{tabular}{|c|c|c|c|c|}
\hline $\begin{array}{l}\text { Lot } \\
\text { No. }\end{array}$ & Lacquer type & $\begin{array}{l}\text { Total } \\
\text { gain nn } \\
\text { weight }\end{array}$ & $\begin{array}{c}\text { Gain in } \\
\text { weight } \\
\text { of lacquer } \\
\text { fllm. }\end{array}$ & $\begin{array}{c}\text { Gain in } \\
\text { weight } \\
\text { of CaCl } \\
\text { weight } \\
\mathrm{H}_{2} \mathrm{O} \\
\text { passed } \\
\text { through } \\
\text { lacquer } \\
\text { film }\end{array}$ \\
\hline $\begin{array}{l}1 \\
2 \\
3\end{array}$ & $\begin{array}{l}\text { Phenol condensation..... } \\
\text { Not designated } \\
\text { Nitrocellulose.............. }\end{array}$ & $\begin{array}{r}0 \\
0.0222 \\
.1789 \\
.1024\end{array}$ & $\begin{array}{l}g \\
0.0087 \\
.0032 \\
.0026\end{array}$ & $\begin{array}{l}g \\
0.0135 \\
.1757 \\
.0998\end{array}$ \\
\hline
\end{tabular}

The rate of moisture absorption and stain spotting does not decrease appreciably with a considerable increase in the thickness of the lacquer film. Thus, when the film thicknesses of lacquers (2 and 3, Table 4) were increased 100 per cent there was only a 10 per cent reduction in the permeability to moisture. An increase of 100 per cent in the thickness of a single lacquer film on specimens coated with these lacquers caused no noticeable decrease in the amount or rate of stain spotting. It is evident from Tables 4 and 5 that even though impermeability to moisture is a highly desirable property of a lacquer to resist stain spotting, it is not the only useful property. 
Others may include improved adherence, resistance of the lacquer film to attack by compounds in the pores, or ability to form with such compounds substances which seal the pores or are impermeable.

As the quality of the lacquer had been found to have so great an effect on stain spotting, numerous samples of commercial and experimental lacquers (also tested for crystal spotting) were compared by the following method:

Test for stain spotting of brass plated gray iron castings.-A large number of piec es of a type known to be subject to stain spotting, preferably cast in the same lot, are sampled after the customary machining and polishing. At least 10 and preferably 25 specimens are selected at random for each set of experiments. They are then treated as follows:

1. Clean electrolytically as cathode for three minutes in a solution containing $60 \mathrm{~g} / 1$ (8 oz./gal.) of sodium carbonate, $7.5 \mathrm{~g} / 1$ (1 oz./gal.) of sodium cyanide, and $7.5 \mathrm{~g} / \mathrm{l}\left(1 \mathrm{oz} / \mathrm{gal}\right.$.) sodium hydroxide at $60^{\circ} \mathrm{C}$. $\left(140^{\circ} \mathrm{F}.\right)$, and rinse in warm water.

2. Pickle for about one minute in hydrochloric acid (1 part concentrated hydrochloric acid to 2 parts by volume of water) and rinse in cold water.

3. Clean electrolytically for one minute as in 1.

4. Brass plate at room temperature for 40 minutes at approximately $0.3 \mathrm{amp} / \mathrm{dm}^{2}$ (3 amp/sq. ft.) in a regular brass plating solution; for example, one containing-

Copper cyanide, CuCN

Zinc cyanide, $\mathrm{Zn}(\mathrm{CN})_{2-\ldots}$

Sodium cyanide, $\mathrm{NaCN}$

Sodium carbonate, $\mathrm{Na}_{2} \mathrm{CO}_{3} \ldots$

Ammonium hydroxide (sp. gr. 0.90)

5. Rinse the specimens in hot water, allow to dry in the air, and store them for 24 hours in an atmosphere with high humidity (for example, in a closed space containing an open vessel of water) in order to permit them to spot out. (This step has been found to be the most effective mans of removing excessive amounts of the chemicals from the pores, which would otherwise destroy the lacquers. It may be omitted if the castings are not extremely porous. All comparable tests should be made under the same conditions.)

6. Scratchbrush the articles with pumice and water to remove the stains and to produce a dull brass finish, rinse, and dry.

7. Dip into lacquer, allow the coating to dry, and apply baking or other treatment suitable to the lacquer employed. In order to produce lacquer films of approximately equal thickness, dilute the lacquer with thinner until it just produces an iridescent film on a dipped metal specimen. Then add just enough lacquer to prevent the formation of this iridescence.

$47559^{\circ}-29-8$ 
8. Expose the articles to a high humidity at $20^{\circ}$ to $30^{\circ} \mathrm{C}$. $\left(68^{\circ}\right.$ to $86^{\circ} \mathrm{F}$.); for example, over water in a closed vessel. Examine the samples at the end of 2,4 , and 24 hours, and every 24 hours thereafter for a week, and note the number and extent of the spots.

The castings employed were taken at random from a lot of 600 gray iron "catch cases." In each experiment 10 castings were used, and each lacquer was tested with two lots of 10 each, prepared on different days. The average of the 20 samples are reported in Table 5. By "badly spotted" is meant conspicuous or numerous spots. "Lightly-spotted" samples are those on which the spots are noticeable but not conspicuous. The total spotting, that is, the sum of the two preceding columns-represents the proportion that would probably be rejected by a careful inspection.

\section{TABLE 5.-Effects of lacquers on stain spotting}

[Exposed to high humidity for 1 week]

GROUP I

\begin{tabular}{|c|c|c|c|c|c|c|c|}
\hline \multirow{2}{*}{$\begin{array}{l}\text { Lot } \\
\text { No. }\end{array}$} & \multirow{2}{*}{ Lacquer type (as designated by manufacturer) } & \multicolumn{2}{|c|}{$\begin{array}{c}\text { Temperature of } \\
\text { baking }\end{array}$} & \multirow{2}{*}{$\begin{array}{l}\text { First } \\
\text { appear- } \\
\text { ance of } \\
\text { spots } \\
\text { days }\end{array}$} & \multicolumn{3}{|c|}{$\begin{array}{c}\text { Condition after one } \\
\text { week }\end{array}$} \\
\hline & & ${ }^{\circ} \mathrm{C}$. & ${ }^{\circ} \mathrm{F}$. & & $\begin{array}{l}\text { Badly } \\
\text { spotted }\end{array}$ & $\begin{array}{l}\text { Lightly } \\
\text { spotted }\end{array}$ & $\begin{array}{l}\text { Total } \\
\text { spotted }\end{array}$ \\
\hline $\begin{array}{l}1 \\
4 \\
6 \\
8 \\
9\end{array}$ & $\begin{array}{l}\text { Phenol-condensation resin } \\
\text { Not designated }\end{array}$ & $\begin{array}{r}135 \\
50 \\
50 \\
50 \\
50\end{array}$ & $\begin{array}{l}275 \\
122 \\
122 \\
122 \\
122\end{array}$ & $\begin{array}{l}2 \\
1 \\
6 \\
4 \\
1\end{array}$ & $\begin{array}{r}\text { Per cent } \\
20 \\
5 \\
0 \\
0 \\
15\end{array}$ & $\begin{array}{r}\text { Per cent } \\
0 \\
10 \\
10 \\
10 \\
5\end{array}$ & $\begin{array}{r}\text { Per cent } \\
20 \\
15 \\
10 \\
10 \\
20\end{array}$ \\
\hline $\begin{array}{l}12 \\
15 \\
18 \\
24\end{array}$ & $\begin{array}{l}\text { Phenol-condensation resin } \\
\text { Not designated }\end{array}$ & $\begin{array}{r}50 \\
135 \\
50 \\
135\end{array}$ & $\begin{array}{l}122 \\
275 \\
122 \\
275\end{array}$ & $\begin{array}{l}1 \\
3 \\
1 \\
1\end{array}$ & $\begin{array}{r}15 \\
5 \\
15 \\
10\end{array}$ & $\begin{array}{r}5 \\
0 \\
10 \\
10\end{array}$ & $\begin{array}{r}20 \\
5 \\
25 \\
20\end{array}$ \\
\hline
\end{tabular}

GROUP II

\begin{tabular}{|c|c|c|c|c|c|c|c|}
\hline $\begin{array}{r}2 \\
14 \\
17 \\
19 \\
20 \\
22\end{array}$ & \begin{tabular}{|l|}
$\begin{array}{l}\text { Not designated } \\
\text { Synthetic gum } \\
\text { Not designated }\end{array}$ \\
do
\end{tabular} & $\begin{array}{l}50 \\
50 \\
50 \\
50 \\
50 \\
50\end{array}$ & $\begin{array}{l}122 \\
122 \\
122 \\
122 \\
122 \\
122\end{array}$ & $\begin{array}{l}1 \\
1 \\
1 \\
1 \\
1 \\
1\end{array}$ & $\begin{array}{l}15 \\
20 \\
15 \\
15 \\
20 \\
30\end{array}$ & $\begin{array}{l}25 \\
25 \\
25 \\
30 \\
30 \\
10\end{array}$ & $\begin{array}{l}40 \\
45 \\
40 \\
45 \\
50 \\
40\end{array}$ \\
\hline
\end{tabular}

GROUP III

\begin{tabular}{|c|c|c|c|c|c|c|c|}
\hline $\begin{array}{r}3 \\
5 \\
7 \\
10 \\
11\end{array}$ & $\begin{array}{l}\text { Nitrocellulose } \\
\text { Not designated } \\
\text { Nitrocellulose and natural resin } \\
\text { Not designated }\end{array}$ & $\begin{array}{l}50 \\
50 \\
50 \\
50 \\
50\end{array}$ & $\begin{array}{l}122 \\
122 \\
122 \\
122 \\
122\end{array}$ & $\begin{array}{ll}1 & 1 \\
1 & 1 \\
1 & 1 \\
1 & 1 \\
1 & 1\end{array}$ & $\begin{array}{l}45 \\
45 \\
45 \\
75 \\
25\end{array}$ & $\begin{array}{l}20 \\
35 \\
30 \\
15 \\
40\end{array}$ & $\begin{array}{l}65 \\
80 \\
75 \\
90 \\
65\end{array}$ \\
\hline $\begin{array}{l}13 \\
16 \\
21 \\
23\end{array}$ & $\begin{array}{l}\text { Nitrocellulose and natural resin } \\
\text { Synthetic resin } \\
\text { Not designated }\end{array}$ & $\begin{array}{l}50 \\
50 \\
50 \\
50\end{array}$ & $\begin{array}{l}122 \\
122 \\
122 \\
122\end{array}$ & $\begin{array}{ll}1 & 1 \\
1 & 1 \\
1 & 1 \\
1 & 1\end{array}$ & $\begin{array}{l}90 \\
15 \\
70 \\
70\end{array}$ & $\begin{array}{r}10 \\
40 \\
5 \\
20\end{array}$ & $\begin{array}{r}100 \\
55 \\
75 \\
90\end{array}$ \\
\hline
\end{tabular}

1 Less than one day.

In Table 5 these lacquers have been divided into three groups. Group I contains those with which less than 25 per cent of the samples spotted, Group II those with 25 to 50 per cent spotted, and Group III those with over 50 per cent spotted. 
Owing to the limited time available, only a few of the lacquers tested in Table 5 have been used in extended laboratory and plant tests. These results are therefore chiefly of value in showing the importance of lacquers in connection with stain spotting and the possibility of developing or selecting the most suitable lacquers for this purpose. Further tests should, therefore, be made by the makers and users of these lacquers. Before adopting any lacquer for commercial work its suitability should be determined by such tests as are described in this paper. In addition, it is necessary in each case to determine by appropriate tests whether the lacquer possesses other qualities essential for a given class of work, such as color, flexibility, and resistance to the effects of light, weathering, and abrasion.

It may be noted by comparing Tables 1 and 5 , that a given lacquer is not necessarily or usually suitable for preventing both types of spotting. Only two samples (6 and 9) were in Group I for each purpose. When otherwise suitable, such a lacquer is desirable for use on castings having a sulphide finish.

\section{(f) THE ENVIRONMENT}

As previously noted, the only constituent of the atmosphere that contributes directly to the stain spotting is the moisture, the absorption of which causes compounds present in the pores to exude. Other substances, such as carbon dioxide and sulphur compounds, may change or affect the color and character of the spots but not their occurrence. The temperature of the air is chiefly of importance to the extent that changes in temperature affect the relative humidity. Thus, a sudden decrease in temperature of a humid atmosphere may bring it to the dew point and cause actual condensation of moisture on the surface, and thus accelerate spotting.

\section{PLANT TESTS}

Observations were made in four different plants upon the behavior of large lots (from 100 to 300 each) of castings prepared by definite procedures. At the time when these tests were made-that is, in September and October, 1928-the extended laboratory tests on lacquers had not been completed. Only a few of these lacquers were, therefore, tested in the plants. To be conclusive, the plant tests must be made when conditions are favorable for spotting, preferably in the humid summer months. The results of the plant tests are valuable chiefly for showing that with different lacquers or different methods of operation results are obtained which are similar and parallel to the results of laboratory tests. By such confirmations they add weight to the results obtained in the laboratory, 
(a) GRAY IRON CASTINGS

A lot of 300 window catches and cupboard turns were machined and polished, cleaned anodically in dilute potash, pickled in $2: 1$ hydrochloric acid, dipped in a weak sodium cyanide solution, cleaned as cathodes in alkali, and brass plated.

These were divided into four lots and finished as follows:

Lot 1 . Wet scratch-brushed with pumice, dried and dip lacquered in a nitrocellulose lacquer, and dried at $40^{\circ}$ to $50^{\circ} \mathrm{C}$.

Lot 2. As in lot 1, but dipped in a phenol-condensation lacquer, baked at $135^{\circ} \mathrm{C}$. $\left(275^{\circ} \mathrm{F}\right.$.).

Lot 3. Allowed to spot out for three days and then finished as in lot 1 .

Lot 4. Allowed to spot out for three days and then finished as in lot 2 .

The samples were then exposed to the air in the lacquer room. The results shown in Table 6 show clearly the superiority of the phenolcondensation lacquer. With this lacquer it was beneficial to allow the specimens to spot before finishing, but with the nitrocellulose lacquer practically all the specimens spotted in a few hours, even when they had been allowed to spot previously, although in the latter case the intensity and extent of the stain spotting were reduced.

TABLE 6.-Spotting of brass-plated gray iron

\begin{tabular}{|c|c|c|c|c|c|}
\hline \multirow{2}{*}{$\begin{array}{l}\text { Lot } \\
\text { No. }\end{array}$} & \multirow{2}{*}{ Finished } & \multirow{2}{*}{ Lacquer } & \multicolumn{3}{|c|}{ Badly spotted } \\
\hline & & & 12 hours & 10 days & 20 days \\
\hline $\begin{array}{l}1 \\
2 \\
3 \\
4\end{array}$ & $\begin{array}{l}\text { Immediately } \\
\text { Aft.... } \\
\text { Afte } 3 \text { days } \\
-\end{array}$ & $\begin{array}{l}\text { Nitrocellulose } \\
\text { Phenol-condensation } \\
\text { Nitrocellulose-.. } \\
\text { Phenol-condensation- }\end{array}$ & $\begin{array}{r}\text { Per cent } \\
100 \\
0 \\
97 \\
0\end{array}$ & $\begin{array}{r}\text { Per cent } \\
100 \\
33 \\
97 \\
0\end{array}$ & $\begin{array}{r}\text { Per cent } \\
100 \\
33 \\
97 \\
0\end{array}$ \\
\hline
\end{tabular}

(b) BRASS AND BRONZE

Cast-brass and bronze escutcheon plates were dipped in a mixture of equal parts of concentrated nitric and sulphuric acids and rinsed, machined and polished, cleaned in gasoline, dipped in concentrated sulphuric acid and rinsed, dried, scratch brushed, treated with potassium polysulphide, scratch brushed, and relieved.

The brass and bronze specimens were each divided into two lots. Lot 1 of each was dipped in nitrocellulose lacquer and baked at $105^{\circ} \mathrm{C}$. $\left(221^{\circ} \mathrm{F}\right.$.) for 45 minutes and lot 2 in phenol-condensation lacquer and similarly baked. They were then exposed to the air in the lacquer room. The results, as shown in Table 7, again show the difference in the values of the two types of lacquers. 
TABLE 7.-Stain spotting of brass and bronze castings

\begin{tabular}{|c|c|c|c|c|c|}
\hline \multirow{2}{*}{$\begin{array}{l}\text { Lot } \\
\text { No. }\end{array}$} & \multirow{2}{*}{ Metal } & \multirow{2}{*}{ Lacquer } & \multicolumn{2}{|c|}{ Spotted } & \multirow{2}{*}{$\begin{array}{l}\text { Badly } \\
\text { spotted, } \\
16 \text { days }\end{array}$} \\
\hline & & & 12 hours & 16 days & \\
\hline $\begin{array}{l}1 \\
2 \\
1 \\
2\end{array}$ & $\mid$\begin{tabular}{|c|} 
Brass \\
Bronze
\end{tabular} & $\begin{array}{l}\text { Nitrocellulose } \\
\text { Phenol-condensation } \\
\text { Nitrocellulose }- \text { Phenol-condensation }\end{array}$ & $\begin{array}{r}\text { Per cent } \\
85 \\
0 \\
85 \\
0\end{array}$ & $\begin{array}{r}\text { Per cent } \\
100 \\
38 \\
100 \\
0\end{array}$ & $\begin{array}{r}\text { Per cent } \\
65 \\
13 \\
64 \\
0\end{array}$ \\
\hline
\end{tabular}

(c) MALLEABLE CAST IRON

About 100 malleable-iron castings were machined and polished, cleaned cathodically in alkali, plated with a very thin copper coat from cyanide bath, brass plated, allowed to spot for 24 hours, and scratch brushed.

One-half were then coated with nitrocellulose and one-half with phenol-condensation lacquer. No numerical data were reported, but the statement was made that the phenol-condensation lacquer greatly reduced the spotting.

(d) REFINISHED CASTINGS

In another plant a large number of brass, bronze, and cast-iron pieces, each of which had been previously finished by the usual procedure, including a nitrocellulose lacquer, and had spotted badly, were refinished by the same process, except that three different lacquers were used. The results of exposure to the plant atmosphere were as shown in Table 8.

TABLE 8.-Stain spotting of refinished articles

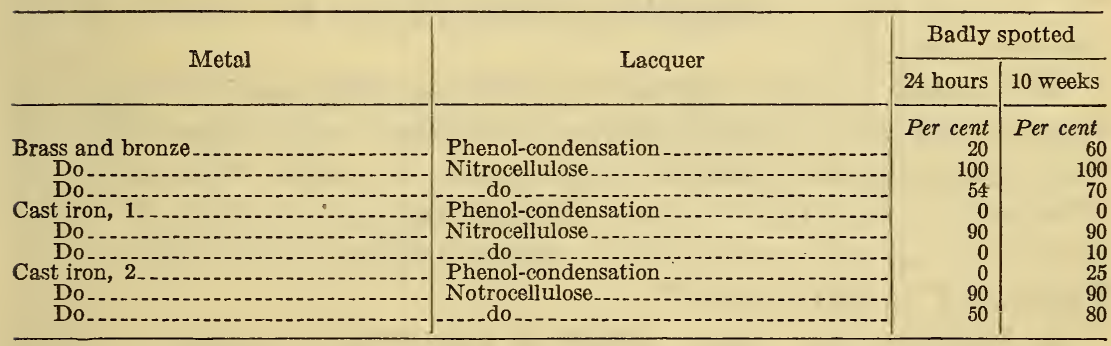

These results are especially significant because they show that evien on specimens known to be so porous as to have spotted badly the phenol-condensation lacquers are somewhat superior to the nitrocellulose.

\section{CONCLUSIONS}

1. Stain spots occur on both lacquered and unlacquered specimens.

2. Stain spots occur on either oxidized or unoxidized finishes.

3. Stain spots occur on both plated and unplated materials.

4. Stain spots usually involve at least three factors-(a) porosity of the metal; $(b)$ the presence in the pores of hygroscopic (moisture absorbing) compounds occluded or formed by the action of alkaline 
or acid cleaning, plating, or coloring solutions; and (c) the absorption of moisture by the compounds in the pores. This may cause the salts to "creep" out over the surface, producing a stain and in extreme cases a crystallization of solid material on the surface of the object within the area of the stain.

5. Stain spotting usually occurs under humid conditions within a few hours or at most a few days, depending on the type of lacquer film employed.

6. The amount of stain spotting may be reduced by using a less porous base metal.

7. Stain spotting may be slightly reduced on plated materials by burnishing the surface; that is, by dry barrel tumbling or rolling.

8. While stain spotting may be reduced under certain conditions by the elimination of alkaline cleaning or plating solutions from the procedure, this expedient is very seldom practical in plant operations.

9. Stain spotting may be reduced by allowing the articles to spot out for 24 hours or more prior to the final finishing and lacquering.

10. The best general remedy for the reduction of stain spotting is the use of satisfactory lacquer films.

\section{ACKNOWLEDGMENTS}

The author is indebted to the following firms for specimens for experimental purposes and for cooperation in plant tests: American Hardware Corporation, Chase Cos. (Inc.), Chantrell Hardware \& Tool Co., Peck, Stow \& Wilcox Co., Penn Hardware Co., Sargent \& Co., Scovill Manufacturing Co., Stanley Works, and Yale \& Towne Manufacturing Co.

The author wishes to thank the following companies for supplying lacquers for experimental purposes or plant tests: Agate Lacquer Manufacturing Co., Bakelite Corporation, Canadian Hanson \& Van Winkle Co., Egyptian Lacquer Manufacturing Co., Maas \& Waldstein Co., Murphy Varnish Co., Stanley Chemical Co., Waukegan Chemical Co., and Zapon Co.

In addition, the author wishes to express appreciation to many individuals, including the staffs of the above companies and members of the American Electroplaters' Society and its research committee, who have furnished information and suggestions.

Finally, the author wishes to express appreciation to Dr. William Blum, of the Bureau of Standards, for advice and helpful criticism during the progress of this investigation.

Washington, March 9, 1929. 